\title{
Effect of an Educational Program on Gynecological Nurses' Performance Pre and Post Hysterectomy Surgery
}

\author{
Aya Nasr Mahmoud ${ }^{1}$, Azza Fouad El-Adham², Shimaa Mohamed Hashem ${ }^{3}$ \\ ${ }^{1}$ Demonstrator in Maternity and Gynecological Nursing Dept, Faculty of Nursing, Tanta University, \\ Egypt \\ ${ }^{2}$ Assist. Prof. of Maternity and Gynecological Nursing Dept, Faculty of Nursing, Tanta University, \\ Egypt \\ ${ }^{3}$ Lecturer of Maternity and Gynecological Nursing Dept, Faculty of Nursing, Tanta University, Egypt.
}

\begin{abstract}
Background: Hysterectomy is the most common gynecological surgical procedure among reproductive age women. The nursing care plan for a woman undergoing hysterectomy should reflect nurse's awareness of the physical care required, as well as her emotional needs and anxiety levels. The aim of this study: was to determine the effect of educational program on gynecological nurses' performance pre and post hysterectomy surgery. Subjects and method: The study was conducted at the gynaecological inpatient unit of obstetric and gynaecological department at Tanta University Hospital and El-Menshawy Hospital affiliated to Ministry of Health and Population. All nurses (40 nurses) who were working in the previously mentioned settings and provided care to women undergoing hysterectomy were included in the study. Two tools were used for data collection; Tool (I): Structured interview schedule for nurses. Tool (II): An observational checklist for nurse's performance. Results: The results revealed that majority of the studied nurses had low level of knowledge and unsatisfactory performance regarding hysterectomy preprogram, which significantly improved immediately and one month post program with a significant statistical difference $\mathrm{P}<0.05$. Conclusion and recommendations: The findings of present study revealed that the implementation of the educational program resulted in a significant improvement of nurses' performance regarding pre and post hysterectomy surgery immediately and one month after program compared to preprogram. Planned sustainable training program to upgrade nurse's skills and knowledge to care for women with hysterectomy.
\end{abstract}

Keywords: Hysterectomy, Educational Program, Performance and Evidence Based Practices. 


\section{Introduction}

Hysterectomy is the second most common operative procedure performed worldwide following cesarean section ${ }^{(1-3)}$. It is the most commonly performed gynecological surgical procedure in both developed and developing countries. Worldwide, the annual hysterectomy rates vary among different countries ranging from 1.2 to 4.8/1000 women. In the USA, hysterectomy is the most common nonpregnancy related major surgery done. About 600,000 hysterectomies are performed annually in the United States ${ }^{(4-}$ 6). In Nigeria, $28 \%$ of all major gynecological operations performed are hysterectomies. While in Egypt, the incidence of hysterectomy at El kaser $\mathrm{Al}$ Eini hospital in 2009 was $(0.66 \%)$, this incidence was doubled year by year to be $(1.15 \%)$ in 2010 according to (Kaser Al Eini hospital statistical sinuses, 2010) ${ }^{(7-9)}$. Hysterectomy is the surgical removal of the uterus which may also involve removal of the cervix, fallopian tubes, ovaries and other surrounding structures depending on the type of procedure that is performed ${ }^{(10,}$ 11). There are three main types of hysterectomy namely: total, subtotal and radical hysterectomy. In a total hysterectomy, the uterus and cervix are completely removed. While, in a subtotal hysterectomy only the uterus is removed leaving the cervix in situ. On the other hand, in a radical hysterectomy the uterus, cervix, upper vagina and parametrium, ovaries, oviducts, lymph nodes and lymph channels are removed. The type of hysterectomy performed depends on the reason for the procedure ${ }^{(12,13)}$.

There are different reasons for performing hysterectomy including both benign and malignant conditions of the uterus. Benign indications for hysterectomy include uterine fibroids, menstrual disorders, adenomyosis of the uterus, endometriosis, uterine prolapse, abnormal uterine bleeding, chronic pelvic pain, uterine leiomyomas, septic abortions, pelvic inflammatory disease, ectopic pregnancy and precancerous lesions of the endometrium and the cervix ${ }^{(14,15)}$. On the other hand, malignant indications for hysterectomy include cervical cancer, endometrial carcinoma, malignant ovarian tumor and malignant disease of other adjacent organs. Hysterectomy can be performed abdominally, vaginally, laparoscopy or the combination of both vaginal and laparoscopy procedures. The consequences of this surgical procedure can affect the health of many women ${ }^{(16,17)}$. Hysterectomy has intense effect on a women's health as the women stand facing 
physical, psychological, emotional and social problems after the operation. The possible physical complications of hysterectomy include problems with anesthesia, surgical wound infection, fever, wound hematoma, excessive bleeding, risks of blood transfusion, urinary and bowel injuries and injury to a major blood vessel. Physical complications also include urinary tract infection, nerve damage, loss of ovarian function, postoperative thromboembolism, early onset of menopause, myocardial infarction, pneumonia, sepsis, fluid and metabolic imbalance $(18,19)$. Additionally, some women may suffer from psychological problems as anxiety, depression and psychosexual problems. While at the social effect of hysterectomy on women's quality of life include marriage problems which in some cases ended by divorce. So, gynecological nurses can play a vital role in improving the quality of life among women undergoing hysterectomy, if they were prepared to perform high quality care pre and post hysterectomy surgery ${ }^{(20,21)}$.

Gynecological nurses are responsible for many aspects of care for women undergoing hysterectomy. This includes assessment, analysis, planning, implementation and evaluation of the women. Nurses are the primary caregivers once a patient is admitted to the hospital, throughout hospital stay and even after discharge (22). Providing education for nurses regarding pre and postoperative care of women undergoing hysterectomy is a very important issue of nursing care. It can improve nurses' knowledge and performance through implementation of a high quality, cultural sensitive and evidence based nursing practice to hysterectomy women. Proper nursing performance can affect the patients coping pre and post hysterectomy surgery. Studies show that patients who have been prepared and trained well before operation need fewer analgesics, antiemetic and sedatives. Moreover, they recover faster after the operation, with a shortened hospital stay and early discharged ${ }^{(23,24)}$.

Consequently, gynecological nurses can provide preoperative education for hysterectomy patients in order to increase their sense of self-respect and psychological well-being and to decrease their anxiety. On the same line, implementation of postoperative care given by well-trained and skilled nursing staff will ensure restoration of physiological functions, promoting healing of tissues and recognizing and managing complications ${ }^{(25)}$.Additionally, the gynecological nurse's role is extended to 
preparing the patient and her family for discharge through an on-going process that takes place among the whole period of hospitalization (26). Prior to discharge, verbal and written instructions are to be provided to the patient and her family, including nutrition, wound care, personal hygiene, activity restrictions, guidelines for medication administration, signs and symptoms of infection to report, and follow up appointments ${ }^{(27,28)}$.

Provision of comprehensive nursing care before and after hysterectomy by a skilled nurse is the single most important way of reducing post-hysterectomy complications and saving women's lives. Provision of comprehensive pre and postoperative nursing care is also a moral and ethical issue, as the right to life and health is a social human right. Thus, all women should be guaranteed the right to comprehensive gynecological nursing care especially pre and post hysterectomy surgery $(29,30)$. Hence, this study was conducted to determine the effect of educational program on gynecological nurses' performance pre and post hysterectomy surgery.

\section{The aim of this study was to:}

Determine the effect of educational program on gynecological nurses' performance pre and post hysterectomy surgery.

\section{Research Hypothesis:}

Nurses who attend an educational program regarding on gynecological nurses performance pre and post hysterectomy surgery exhibit higher knowledge and level of performance than those who did not attend.

\section{Subjects and method:}

\section{Study Design:-}

A quasi-experimental research design was used to conduct this study.

\section{Setting:-}

The study was conducted at the gynaecological inpatient unit of obstetric and gynaecological department at Tanta University Hospital and El-Menshawy Hospital affiliated to Ministry of Health and Population.

\section{Subjects:-}

All nurses (40 nurses) who were working in the previously mentioned settings and provided care to women undergoing hysterectomy were included in the study and they were classified as follow:

- Nurses who were working at Tanta University Hospital (30 nurses).

- Nurses who were working at ELMenshawy Hospital (10 nurses).

Tools of data collection: 
Two tools were developed and used by the researcher to achieve the aim of the study:

\section{Tool I: Structured interview schedule} for nurses:

This tool was developed by the researcher after reviewing the recent related literature $(8,24)$ to assess socio-demographic characteristics and knowledge of the nurses regarding hysterectomy and pre and postoperative care of women undergoing hysterectomy. It comprised the following parts:

Part (1): Socio - demographic characteristics of nurses:

This part included: (name, age, marital status, workplace, phone number, educational level, occupation, years of experience and previous training courses regarding care of women undergoing hysterectomy, last course and organization that organized this course and if the department has any teaching aids (its type).

Part (2): Nurses' Knowledge Assessment

\section{Sheet:}

It was developed by the researcher to assess nurses' knowledge before and after implementation of the educational program. It included:

a- Nurses' knowledge regarding hysterectomy: It included nurse's knowledge about female reproductive system, hysterectomy surgery and knowledge about health education of selfcare for women undergoing hysterectomy before discharge from the hospital.

b- Nurses' knowledge regarding pre and post-operative care of women who undergo hysterectomy as follow: nurse's knowledge about nursing care before and after hysterectomy.

\section{Scoring system of knowledge-:}

Correct and complete answers were scored as two points, Correct and incomplete answers were scored as one point and incorrect answers and didn't know were scored as zero point.

The total score for knowledge was calculated as follows:

- High level of knowledge $\geq 75 \%$.

- Moderate level of knowledge $60 \%$ $<75 \%$.

- Low level of knowledge $<60 \%$.

Tool II: An observational checklist for nurse's performance: This tool was developed by the researcher after reviewing the recent related literature $(22,29)$ to assess nurses' performance regarding hysterectomy before and after implementation of the educational program. It comprised the following parts:

Part (a): Pre-operative assessment of nurse's performance: It was developed by the researcher to assess nurses' performance regarding pre-operative care. 
It included pre-operative nursing care and procedures provided by nurses to women during pre-operative period. These included: assessment of fundamental procedure, admission procedure, preoperative psychological and physical preparations, vital signs monitoring, routine preoperative screening tests, omission of mechanical bowel preparation before surgery, preoperative fasting instructions, administration of preoperative intravenous fluids, skin preparation and cleansing, record voiding time and amount as bladder preparation, remove makeup, nail polish, dentures and jewelers and post procedure tasks.

\section{Part (b): Post-operative assessment of} nurse's performance: It was developed by the researcher to assess nurses' performance regarding post-operative care and procedures provided by nurses given to women during post-operative period. It included assessment of nurses' performance of the following: immediate postoperative care, vital signs monitoring, assessment of signs of hemorrhage, the incision site, bowel sound, enhancement of early ambulation, provide respiratory care, early urinary catheter removal, enhancement of early fluid intake, early oral feeding, methods to control nausea and vomiting, measures to relief post- operative pain, deep vein thrombosis prophylaxis, physical and psychological teaching and support and post procedure tasks.

\section{The total score level of the nurses' performance was classified as follows:}

Done correctly and completely were scored as two point, done correctly and incompletely were scored as one point and done incorrect or not done at all were scored as Zero.

\section{The total score for practice was calculated as follows:}

-Unsatisfactory performance $<60 \%$.

- Satisfactory performance $\geq 60 \%$.

\section{Method}

The study was conducted according to the following steps-:

1) Official letter clarifying the purpose of the study was obtained from the Faculty of Nursing, Tanta University and submitted to the responsible authorities of the selected settings for permission to carry out the study.

2) Ethical and legal considerations:

a. Approval of ethical committee of Faculty of Nursing, Tanta University was obtained.

b. All participants were informed about the purpose of the study.

c. An informed consent was taken from every participant in the study 
included the right to withdraw at any time.

d. The researcher ensured that the nature of the study didn't cause any harm or pain for the entire sample.

e. Confidentiality and privacy were taken into consideration regarding data collection.

3) Tool I was developed in Arabic and Tool II was developed in English after reviewing recent related literature and were tested for content and construct validity by 5 experts in obstetric and gynaecological nursing field. Accordingly corrections and modifications were done. The validity of the expertise judgments of the questions of the Arabic translated version of the studied nurses knowledge and performance regarding hysterectomy surgery was 0.98 and 0.96 respectively. The reliability of the translated Arabic tools was done by using Cronbach's Alpha which was 0.87 and 0.88 respectively.

4) A pilot study was carried out on $10 \%$ of the sample (4 nurses) of the proposed sample after taking their approval to test the feasibility, and applicability of the developed tools and to determine obstacles that may be encountered during period of data collection. According to the results obtained, some statements of Tool I and II were rephrased and the obtained data were excluded from the study sample .

5) Tool I and Tool II were used to assess nurses' knowledge and performance before, immediately and one month after implementation of the educational program.

6) Data collection was conducted in a period ranged from the beginning of December 2019 to the end of May 2020. Data were collected from EL-Menshawy Hospital followed by Tanta University Hospital in morning and afternoon shifts, until the predetermined sample size was collected. The researcher attended 2-3 days per week in the study setting.

7) The educational program was conducted through four phases:

\section{Phase I: Assessment phase:}

- This phase was done before giving sessions. The researcher met with nurses at morning and afternoon shifts at the gynecological ward of Tanta University Hospital and EL-Menshawy Hospital. Nurses were asked to participate in the study after explaining the aim of the study. After that, nurses were assessed using Tool (I) part 1 to collect baseline data (socio-demographic characteristics) and Tool (I) part 2 and Tool II were used to assess nurses' knowledge and performance related to hysterectomy 
surgery before, immediately and one month after implementation of the educational program .

- Nurses' pre-test was distributed at the beginning of the session using Tool I Part II to assess nurses' knowledge regarding hysterectomy surgery in the presence of the researcher for necessary clarification.

Tool II the observational checklist parts a and $\mathbf{b}$ (pre and post-operative procedures) was used to assess nurses' performance regarding hysterectomy surgery before, immediately and one month after implementation of the educational program.

- Nurses' knowledge was assessed individually for each nurse by an interview lasted 15-20 minutes for each nurse .

-Nurses' performance was assessed by the researcher individually for each nurse for every procedure.

\section{Phase II: Planning phase:}

a- Preparation of the educational program sessions:

- The teaching program included 4 sessions for each group. It was carried out in the previously mentioned settings. The total number of nurses was (40 nurses), they were divided into 4 main groups. Each group included 10 nurses which divided into two equal sub-groups (5 nurses) due to the effect of COVID 19 Pandemic; six sub-groups at Tanta University Hospital and two sub-groups at El-Menshawy Hospital. The content was presented during 2-3 days per week. The duration of each session ranged from one and half hour to two hours including periods of discussion.

\section{b- Setting the goals and objectives of the} program:

- The goal of the program was to:

- Enhance nurses' performance pre and post hysterectomy surgery.

- Objectives of the program:

-Improving the knowledge and performance scores of nurses.

\section{c- Preparing the content of the program:}

-An educational booklet was developed by the researcher based on nurse's needs and data from the assessment phase, using recent relevant literature available locally and internationally (books, magazines). The booklet was distributed to every nurse to increase nurses' knowledge about hysterectomy and care measures needed, as well as for encouragement and being a reference. The program included: different methods of teaching as lecture, group discussion, posters, power point 
presentation and demonstration and redemonstration .

\section{Phase III: Implementation phase:}

- The educational program was implemented by the researcher through the following four sessions .

\section{First Session:}

- The researcher explained parts and functions of external and internal female reproductive system and provided knowledge regarding hysterectomy surgery which included definition, indications, types, methods, complications, effect of hysterectomy and role of the nurse in caring for women undergoing hysterectomy, definition and objectives of preoperative care, types of data and examinations on admission, assessment of fundamental and admission procedures, preoperative psychological and physical preparations and vital signs monitoring.

\section{Second Session:}

- This session included the implementation of nursing care during pre-operative period through demonstration and re-demonstration of the following procedures: routine preoperative screening tests, omission of mechanical bowel preparation before surgery, preoperative fasting instructions, administration of preoperative intravenous fluids, skin preparation and cleansing, record voiding time and amount as bladder preparation, remove makeup, nail polish, dentures and jewelers and post procedure tasks.

\section{Third Session:}

- This session included knowledge about post-operative care such as definition and objectives of postoperative care, position after hysterectomy, complications after the operation and implementation of post-operative nursing care through demonstration and re-demonstration of immediate postoperative care, vital signs monitoring, assessment of signs of hemorrhage, incision site and bowel sound, enhancement of early ambulation, provide respiratory care, early urinary catheter removal, enhancement of early fluid intake and oral feeding and measures to relief postoperative pain .

\section{Fourth Session:}

- During this session the implementation of post-operative nursing care was continued through demonstration and re-demonstration which included methods to control nausea and vomiting, deep vein thrombosis prophylaxis, physical and psychological 
teaching and support and post procedure tasks. Then the researcher explained health education given to women before hospital discharge regarding self-care measures needed for post hysterectomy women. This included correct nutrition, the importance of cleaning of the perineum, special care for the perineum, hysterectomy exercise, avoidance of physical activities, wound care, methods used to relieve pain in the wound area, signs of wound infection, methods used to reduce anxiety and nervous pressure, sexual intercourse, causes of pain during sexual intercourse and warning signs that require the patient to go immediately to the hospital.

- The educational program was presented through open discussion, demonstration and re-demonstration between the researcher and nurses, visual aids, power point presentation, video presentation, self-learning module, and actual situation .

- In each session a theoretical part was explained followed by demonstration of the nursing procedures by the researcher of the above mentioned practices and re-demonstration by nurses was carried out.

\section{Phase IV: Evaluation phase:}

The evaluation of the implemented program was done through:

- Assessment of nurses' knowledge individually by self-filling Tool I part II before, immediately and one month after implementation of the educational program.

- Assessment of nurses' performance by using Tool II part a and b (observation checklist) while conducting nursing care for hysterectomy women, each nurse was observed individually three times to assess their performance before, immediately and one month after implementation of the educational program .

- Comparison was done three times before, immediately and one month post program to identify the effect of the educational program on nurses' knowledge and performance regarding hysterectomy surgery.

- Statistical Analysis: The collected data were organized, coded, tabulated and statistically analyzed using SPSS software (Statistical Package for the Social Sciences, version 19, SPSS Inc. Chicago, IL, USA). For quantitative data, the range, mean and standard 
deviation were calculated. For qualitative categorical set of the data frequency, percentage or proportion of each category and comparison between two groups were done using Chi-square test $\left(\chi^{2}\right)$. Significance was adopted at $\mathrm{p}<0.05$ for interpretation of the results and tests of significance.

\section{Results:}

Table (1): Shows socio-demographic characteristics of the studied nurses at gynecological inpatient unit. It was observed that nurses' age ranged from 2857 years, with a mean age of 41.65 \pm 8.25 . As regards to their marital status, the majority $(90.0 \%)$ of the studied nurses were married, while the minority $(10.0 \%)$ of them was widow. Concerning their workplace, three quarter $(75 \%)$ of the studied nurses work at Tanta University Hospital and one quarter $(25 \%)$ of them work at El Menshawy Hospital. Regarding educational level of the studied nurses, slightly more than two third $(67.5 \%)$ completed nursing technical diploma, and $27.5 \%$, and $5 \%$ respectively completed nursing technical institute and bachelor of nursing. In relation to their occupation, the vast majority $(95 \%)$ of the studied nurses were nurse, while the minority of them (5\%) was nursing specialists. Moreover, the table also demonstrate that $(62.5 \%)$ of the studied nurses had 20 years of experience or more, $(25 \%)$ had 10 years to less than 20 years of experience and $(12.5 \%)$ had 5 years to less than 10 years of experience, and the vast majority (92.5\%) of the studied nurses didn't take any training courses regarding care for women undergoing hysterectomy.

Figure (1): Shows percent of the studied nurses' total score level about overall knowledge subitems questions for women undergoing hysterectomy pre and post educational program at gynecological inpatient unit. It clarifies that $(12.5 \%)$ of the studied nurses had high level of knowledge about overall knowledge subitems questions pre educational program implementation. This increased to $(92.5 \%)$ immediately after educational program implementation and $(85 \%)$ one month post educational program implementation

Figure (2): Shows percent distribution of the total score level of observed performance of the studied nurses at gynecological inpatient unit about preoperative care for women undergoing hysterectomy pre and post educational program. It displays that $(35 \%)$ of the studied nurses had satisfactory practice regarding preoperative care of women 
undergoing hysterectomy pre educational program implementation, which increased to (92.5\%) immediately after educational program implementation, and (87.5\%) one month post educational program implementation.

Figure (3): Shows percent distribution of the total score level of observed performance of the studied nurses at gynecological inpatient unit about postoperative care for women undergoing hysterectomy pre and post educational program. It illustrates that $(25 \%)$ of the studied nurses had satisfactory practice regarding postoperative care for women undergoing hysterectomy pre educational program implementation, which increased to $(87.5 \%)$ immediately after educational program implementation, and (80\%) one month post educational program implementation.

Figure (4): Shows percent distribution of the total score level of the studied nurses at gynecological inpatient unit about overall performance regarding pre and post operative care pre and post educational program. It reveals that $(27.5 \%)$ of the studied nurses had satisfactory practice regarding pre and post - operative care for women undergoing hysterectomy pre educational program implementation, which increased to (90\%) immediately after educational program implementation and $(85 \%)$ one month post educational program implementation.

Table (2): Shows correlation between socio- demographic characteristics and total knowledge and total performance pre, immediately and one-month post educational program implementation among the studied nurses at gynecological inpatient unit. A significant correlation was found between total score of knowledge and nurses' age pre and one month post educational program implementation where $\mathrm{r}=0.354$ and $\mathrm{P}=0.022 *$ and $\mathrm{r}=0.534$ and $\mathrm{P}=<0.001 * *$ respectively. $\quad$ A significant correlation was also found between total score of knowledge and years of experience immediately after educational program implementation and one month post educational program implementation where $\mathrm{r}=0.627$ and $\mathrm{P}=<0.001 * *$ and $\mathrm{r}=0.362$ and $\mathrm{P}=<0.001 * *$ respectively. Moreover, A significant correlation was noticed between total score of performance and nurses' age pre educational program implementation and one month post educational program implementation where $\mathrm{r}=0.248$ and $\mathrm{P}=0.039^{*}$ and $\mathrm{r}=0.490$ and $\mathrm{P}=<0.001$ ** respectively and also between years of experience one month post educational program implementation where $\mathrm{r}=0.755$ and $\mathrm{P}=<0.001 * *$. 
Table (1): Socio-demographic characteristics of the studied nurses at gynecological inpatient unit $(n=40)$.

\begin{tabular}{|c|c|c|}
\hline Socio-demographic characteristics & $\mathrm{N}=40$ & $\%$ \\
\hline \multicolumn{3}{|l|}{ Age (years) } \\
\hline$<40$ & 15 & 37.5 \\
\hline $40-<50$ & 18 & 45.0 \\
\hline 50 or more & 7 & 17.5 \\
\hline Range & \multicolumn{2}{|c|}{$28-57$} \\
\hline Mean \pm SD & \multicolumn{2}{|c|}{$41.65 \pm 8.25$} \\
\hline \multicolumn{3}{|l|}{ Marital status } \\
\hline Married & 36 & 90.0 \\
\hline Widow & 4 & 10.0 \\
\hline \multicolumn{3}{|l|}{ Workplace } \\
\hline Tanta University Hospital & 30 & 75.0 \\
\hline El Menshawy Hospital & 10 & 25.0 \\
\hline \multicolumn{3}{|l|}{ Educational level } \\
\hline Nursing technical diploma & 27 & 67.5 \\
\hline Nursing technical institute & 11 & 27.5 \\
\hline Bachelor of nursing & 2 & 5.0 \\
\hline \multicolumn{3}{|l|}{ Occupation } \\
\hline Nurse & 38 & 95.0 \\
\hline Nursing specialist & 2 & 5.0 \\
\hline \multicolumn{3}{|l|}{ Experience years } \\
\hline $5-<10$ & 5 & 12.5 \\
\hline $10-<20$ & 10 & 25.0 \\
\hline 20 or more & 25 & 62.5 \\
\hline \multicolumn{3}{|l|}{ Participate in training courses } \\
\hline Yes & 3 & 7.5 \\
\hline No & 37 & 92.5 \\
\hline \multicolumn{3}{|l|}{ If yes, how long: } \\
\hline Two years & 3 & 100 \\
\hline \multicolumn{3}{|l|}{ If yes, the organization that organized this course: } \\
\hline University & 3 & 100 \\
\hline \multicolumn{3}{|c|}{$\begin{array}{l}\text { The department have teaching aids (booklet - poster - brochure) that contain } \\
\text { the role of nursing in caring for women who undergo hysterectomy }\end{array}$} \\
\hline No & 40 & 100 \\
\hline
\end{tabular}




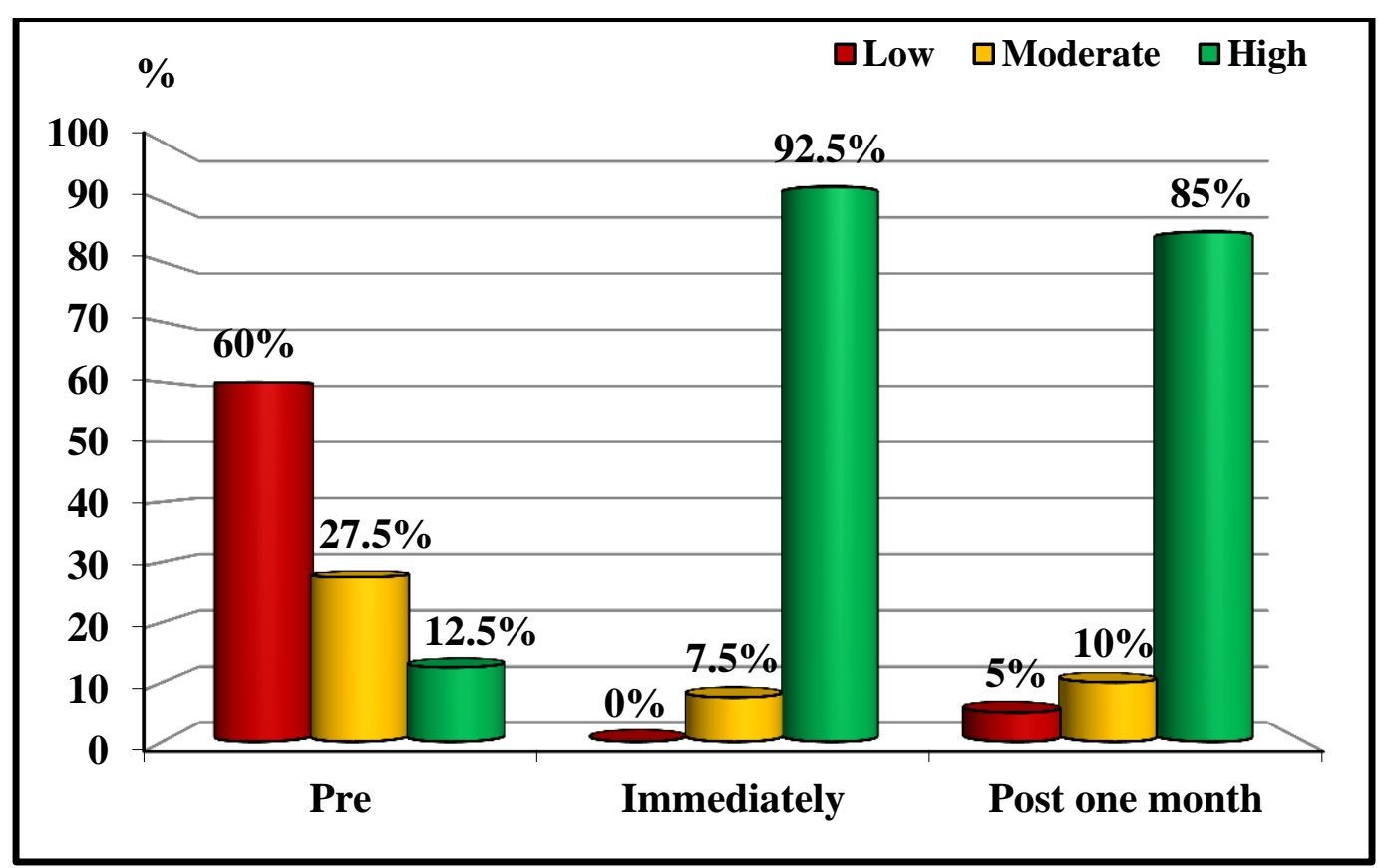

Fig (1): Studied nurses' total score level about overall knowledge subitems questions for women undergoing hysterectomy pre and post educational program at gynecological inpatient unit $(n=40)$.

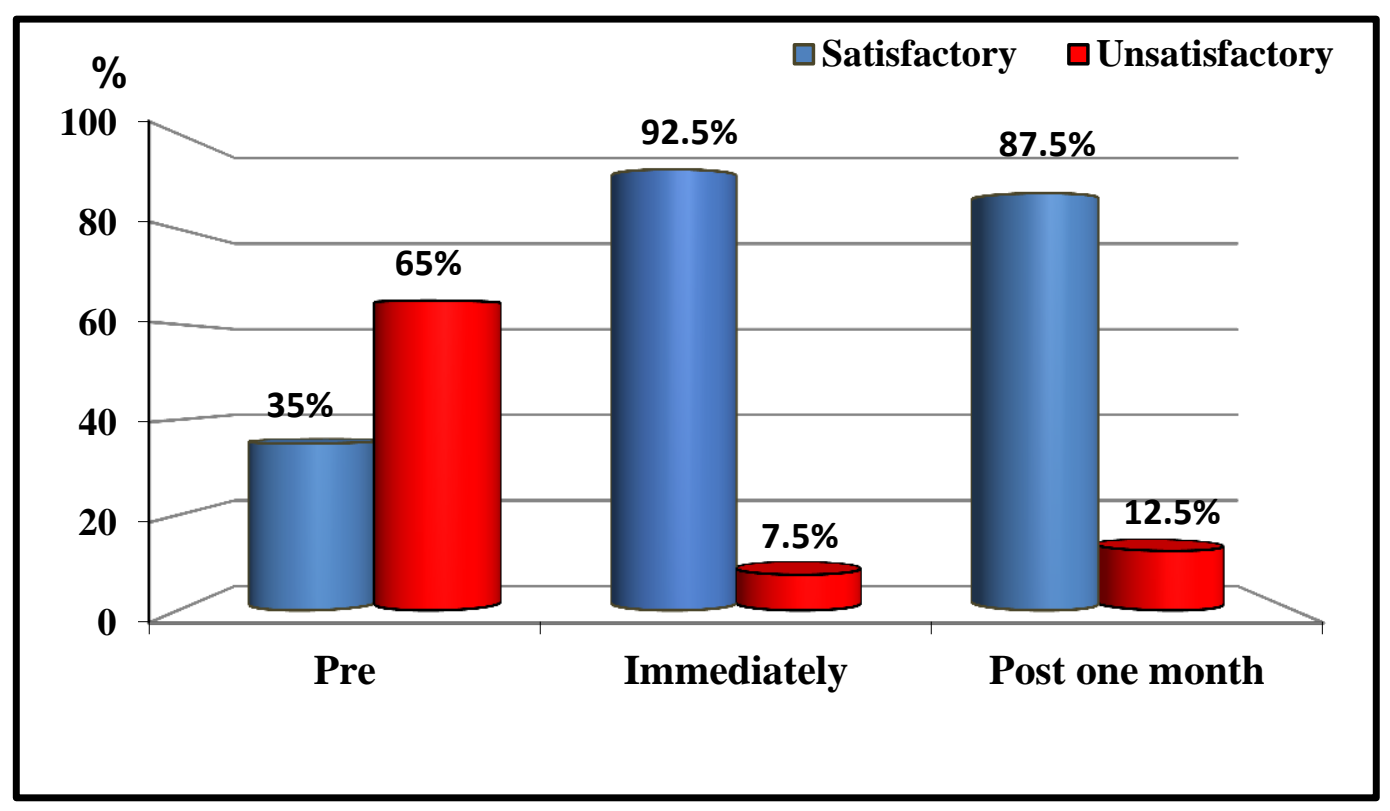

Fig (2): Total score level of observed performance of the studied nurses at gynecological inpatient unit about preoperative care for women undergoing hysterectomy pre and post educational program $(n=40)$. 


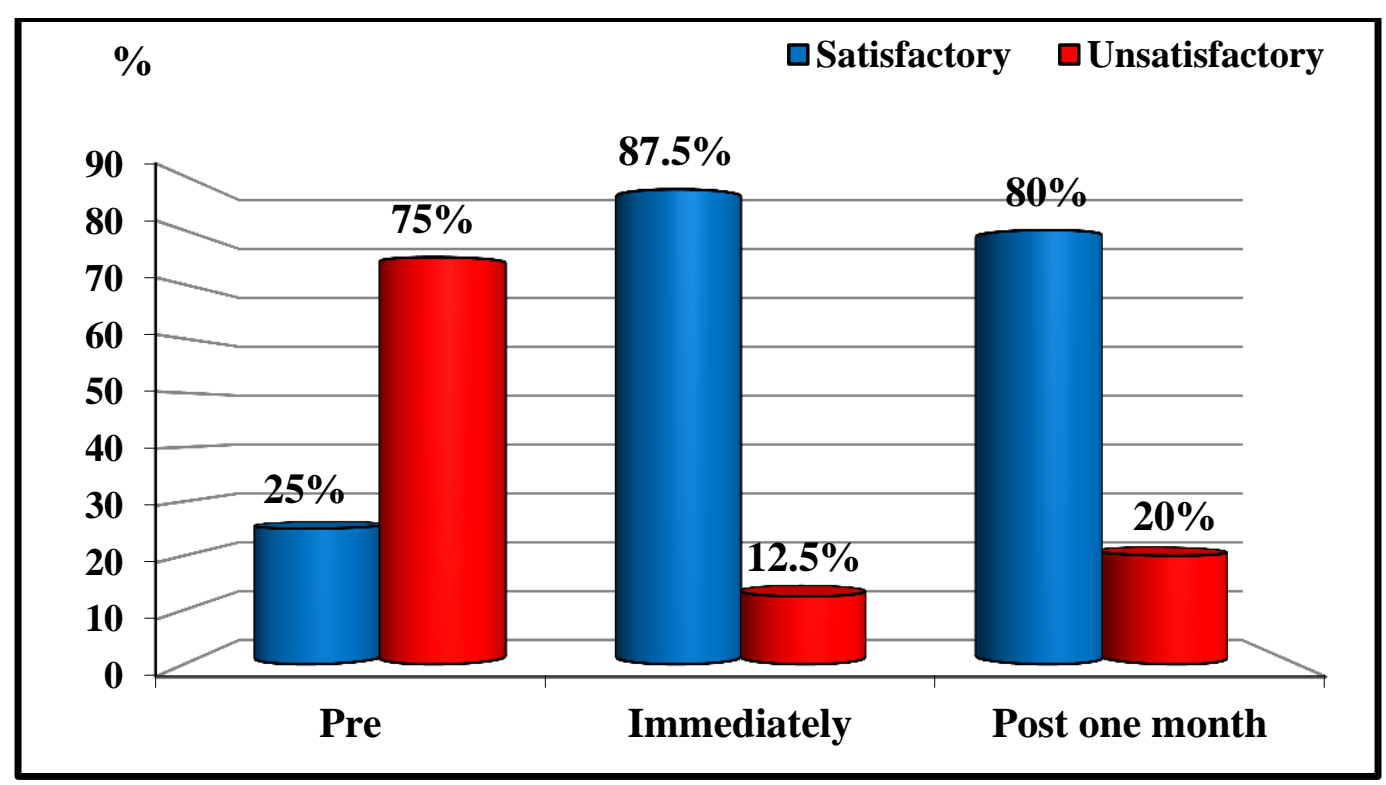

Fig (3): Total score level of observed performance of the studied nurses at gynecological inpatient unit about postoperative care for women undergoing hysterectomy pre and post educational program $(n=40)$.

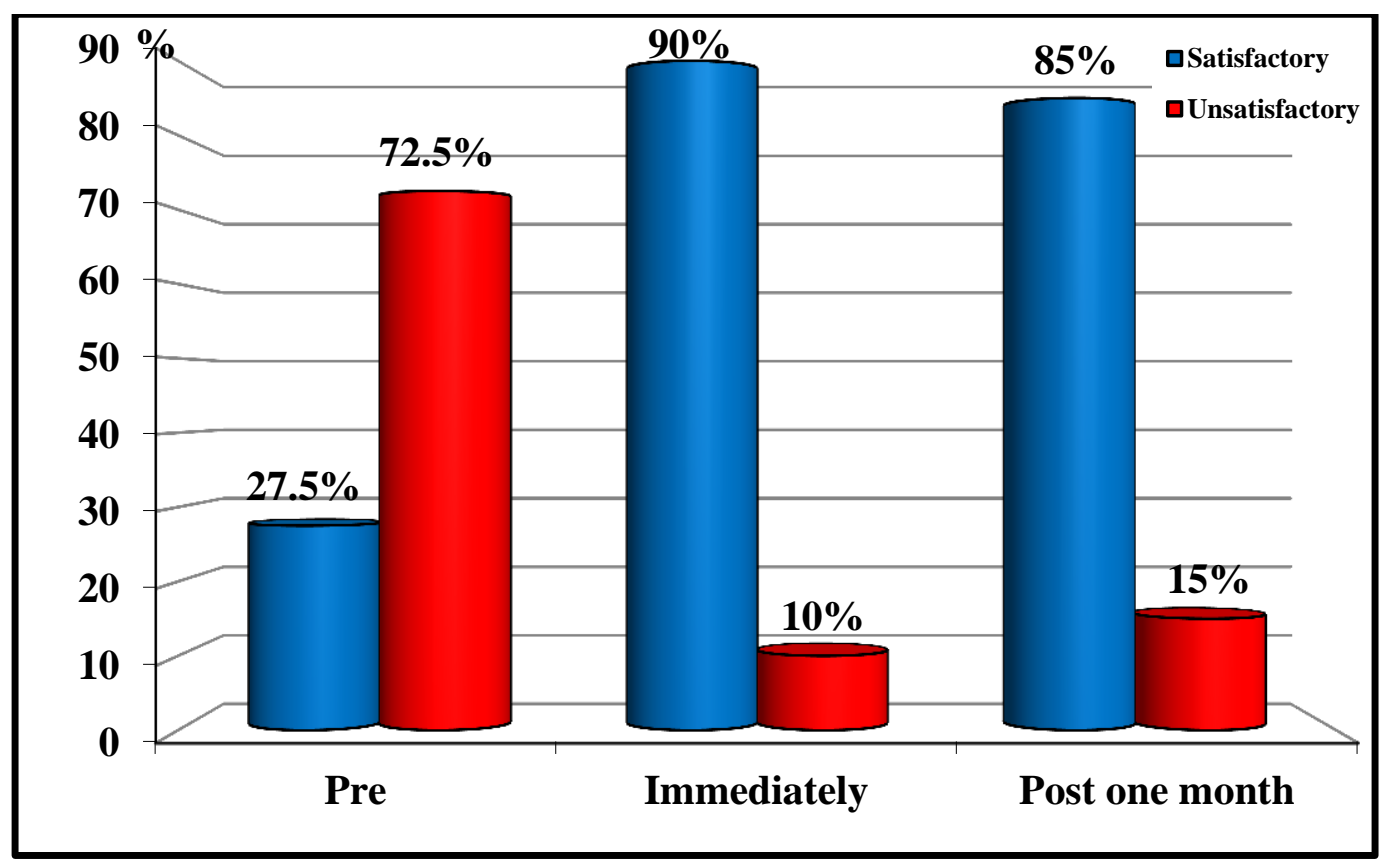

Fig (4): Total score level of the studied nurses at gynecological inpatient unit about overall performance regarding pre and post - operative care pre and post educational program $(n=40)$. 
Table (2): Correlation between socio- demographic characteristics and total knowledge and total performance pre, immediately and one-month post program among the studied nurses at gynecological inpatient unit $(n=40)$.

\begin{tabular}{|c|c|c|c|c|c|}
\hline \multirow{2}{*}{ Socio- demographic data } & \multicolumn{2}{c|}{ Total knowledge } & \multicolumn{2}{c|}{ Total performance } \\
\cline { 3 - 6 } & Pre & 0.354 & $0.022^{*}$ & 0.248 & $0.039^{*}$ \\
\hline \multirow{4}{*}{ Age (years) } & Immediately & 0.126 & 0.096 & 0.240 & 0.064 \\
\cline { 2 - 6 } & Post one month & 0.534 & $<0.001^{* *}$ & 0.490 & $<0.001^{* *}$ \\
\hline \multirow{3}{*}{$\begin{array}{c}\text { Years of } \\
\text { Experience }\end{array}$} & Immediately & 0.152 & 0.125 & 0.047 & 0.723 \\
\cline { 2 - 6 } & Post one month & 0.362 & $<0.001^{* *}$ & 0.755 & $<0.001^{* *}$ \\
\cline { 2 - 6 } & & 0.627 & $<0.001^{* *}$ & 0.158 & 0.432 \\
\hline
\end{tabular}




\section{Discussion}

Reproductive health of women is considered an issue of vital importance. It has a wide spread implications on health, wellbeing and development of the entire population. The concept of total reproductive health includes prevention and treatment of gynecological problems such as uterine fibroids, uterine adenomyosis, uterine prolapse, cervical cancer and endometrial carcinoma ${ }^{(31,32)}$.

Gynecological health is the cinderella of women health promotion. Awareness of gynecological disease is very important for every woman to be able to detect any abnormality or symptoms of gynecological diseases and to seek methods of treatment $(33,34$ ). Hysterectomy is the surgical removal of the uterus and cervix, which is the commonest major gynecological operation used for treatment of many gynecological diseases worldwide. The indications for hysterectomy have changed over the last decade. There are different reasons for performing hysterectomy including both benign and malignant conditions of the uterus. Gynecological nurses are responsible for many aspects of care for women undergoing hysterectomy. This includes assessment, analysis, planning, implementation and evaluation of the women ${ }^{(35,36)}$.
Gynecological nurses should provide both physical and psychological interventions for women undergoing hysterectomy to assist them return to their normal wellbeing as quickly, safely and comfortably as possible, and to prevent complications post hysterectomy surgery. The trend of hysterectomy has been studied by many researchers for many aspects such as indications, approaches, types, new evidence based practice in nursing intervention and pattern of morbidity ${ }^{(37,}{ }^{38)}$.Unfortunately, scarce research exists regarding effect of educational program on nurses' performance pre and post hysterectomy surgery. Thus the aim of this study was to determine the effect of educational program on gynecological nurses' performance pre and post hysterectomy surgery.

\section{Concerning the socio-demographic} characteristics of the studied nurses, the findings of the present study revealed that almost two fifths were 40 to less than 50 years old, the vast majority of them were married, and almost two thirds of them had completed nursing technical diploma. Regarding years of experience, less than two thirds of the studied nurses had 20 years of experience or more. Additionally, the vast majority of the studied nurses 
didn't take any training courses regarding care for women undergoing hysterectomy that may be due to lack of in-service education program. These finding align with Belal Gh et al., (2016) ${ }^{(39)}$ who found that almost half of the studied nurses were 30-45 years old, the majority of them were married, near three quarters of them had secondary technical nursing diploma in nursing and the vast majority of the studied nurses didn't attend any training courses in obstetrical and gynecological nursing. The similarity between both studies may stem from the ignorance of the importance of updating and refreshment courses for nurses to increase their knowledge in maternity hospitals.

On the other hand, this finding is dissimilar to Abd Elhakam E (2010) (40) and Ebrahim E (2016) ${ }^{(41)}$, they pointed out that almost half and slightly less than three fifths of the studied nurses were less than or equal 30 years old respectively, the majority had secondary nursing education and almost two fifths had 10 to 20 years of experience. The finding of the present study also contradicts with Kreem $\mathbf{M}$ and Hamza R (2019) ${ }^{(42)}$ who revealed that two fifths of the studied nurses had (1-5) years of experience and three quarter of them attended training session in nursing. These contradictions may be due to the health setting where the previous studies were conducted enabled their nurses to have refreshing and updating in-service health educational sessions .

Implementation of the present study showed an improvement in the nurses' level of knowledge which is consistent with Hojatallah etal. (2012) (43) and Mohamed N (2015) ${ }^{(44)}$. Regarding total level of knowledge, the current study revealed that three fifths of the studied nurses had low knowledge level pre educational program implementation. This result is supported by Abd Elhakam E (2010) (40), who studied the effect of training program for nurses on nursing intervention for women undergoing hysterectomy and showed that about three fifths of the studied nurses had low knowledge level pre educational program implementation. This might be related to the fact that the majority of the nurses had only nursing technical diploma in which the content was limited in their curriculum and did not receive any previous in-service training program regarding care of women undergoing hysterectomy. In addition, reduction of nurses' knowledge could be due to lack of updating knowledge and overloaded area of working.

Additionally, the majority of the studied nurses in the present study had high level 
of knowledge immediately and one month post educational program implementation. This result is supported by More $\mathbf{U}$ et al., (2020) ${ }^{(45)}$ and also Jacobs $K$ et al., (2018) $)^{(46)}$ who revealed that the majority of the studied subject had good knowledge level regarding hysterectomy post educational program implementation. This improvement might be related to the majority of nurses were excited to learn and have highly expressed their need to learn more about hysterectomy. This finding shows that the educational program had a good impact on improving nurses' knowledge, which could be due to the very focus power point presentation used in each session, as well as using simple Arabic language, clear educational methods and instructional media, in addition to availability of the researcher in the field for more clarification, and frequent repetition of the information of the topic under study.

The gynecological nurse should take an active role in providing patients undergoing hysterectomy with the needed support and care during preoperative period to maximize the benefits and ensure woman's safety ${ }^{(47)}$ In relation to total score level of the studied nurses' performance regarding preoperative care, the present study findings revealed that slightly less than two thirds of the studied nurses had unsatisfactory performance score pre educational program implementation, while immediately and one month post educational program implementation the performance score level was significantly improved. The present study findings strongly agrees with Ebrahim E (2016) ${ }^{(41)}$ who studied professional nurses practical skills regarding women undergoing hysterectomy. The study demonstrated that slightly less than two thirds of the studied nurses had unsatisfactory level of performance score during the assessment of their performance regarding preoperative care. Moreover Abd Elhakam E (2010) ${ }^{(40)}$ revealed that the majority of the studied nurses had significant improvement in performance level about preoperative care with Mean \pm SD $89.6 \pm 5.1$ post educational program implementation. Un satisfactory performance of the studied nurses preprogram may be due to that they have poor level of knowledge and lack of updating in-service educational program and improved after program due to frequent demonstration and providing better teaching and learning materials that enabled learning and better communication about hysterectomy surgery. 
The postoperative period is the final period of the surgery which is a critical time for post hysterectomy women. The nursing care provided to women after operation is a second importance to the operation itself. The objective of postoperative nursing care is to assist women to return to their normal physical and psychological conditions as quickly, safely and comfortably as possible (48). Concerning, the studied nurses' performance regarding postoperative care, the present study findings revealed that three quarters of the studied nurses had unsatisfactory level of performance score pre educational program implementation, while immediately and one post educational program implementation their performance is significantly improved. The present study findings strongly agrees with Ebrahim E (2016) ${ }^{(41)}$ who demonstrated that almost two thirds $(67.8 \%)$ of the studied nurses had unsatisfactory level of performance score during the assessment of their performance regarding postoperative care pre educational program implementation and Abd Elhakam E (2010) ${ }^{(40)}$ also revealed that the majority of the studied nurses had significant improvement in performance level about postoperative care with Mean \pm SD $77.9 \pm 6.4$ post educational program implementation. The similarity between these studies pre educational program implementation may be due to lack of a system for supervision and evaluation of nursing practice which significantly improved post educational program implementation due to the use of different audiovisual material, colored booklet and power point presentation, which enhanced the retention of the information and has positive impact on their performance.

As regarding total nurses' performance scores level about pre and post-operative care for women undergoing hysterectomy, the findings of the present study revealed that less than three quarters of the studied nurses had unsatisfactory level of performance pre educational program implementation. Un satisfactory total nurses' performance about pre and post-operative care for women undergoing hysterectomy owing to lack of orientation and periodic training programs for newly employees nurses . While immediately and one month post educational program implementation the majority of the studied nurses had significant improvement in their performance. This result is supported by Gouda E (2017) ${ }^{(49)}$ who showed that less than three quarters $(70 \%)$ of the studied nurses had unsatisfactory level of performance pre educational program implementation. Moreover, Abd Elhakam 
E (2010) ${ }^{(40)}$ revealed that the majority of the studied nurses $(89.1 \%)$ had significant improvement in total performance score level post educational program implementation.

Finally, regarding correlation between socio- demographic characteristics and total knowledge and total performance pre, immediately and one-month post program, the present study illustrated that a positive statistically significant correlation between total score of knowledge, total score of performance and the studied nurses age pre and one month post educational program implementation. It was also found that there is a positive statistically significant correlation between total score of knowledge and the studied nurses years of experience immediately and one month post educational program implementation. Additionally, a positive statistically significant correlation was found between total score of performance and years of experience one month post educational program implementation. This result is consistent with Abd Elhakam E (2010) (40) who demonstrated a positive statistically significant correlation between total score of knowledge, total score of performance and the studied nurses age pre and one month post educational program implementation. On contrary More $\mathbf{U}$ et al., (2020) ${ }^{(45)}$ demonstrated that there were no correlation between the total score of knowledge, total score of performance and studied nurses age pre and one month post educational program implementation. So, based on the findings of the present study, the research hypothesis has been achieved after implementation of the educational program regarding hysterectomy surgery which resulted in statistically significant improvement of gynecological nurses' performance immediately and one month later compared to pre educational program implementation.

\section{Conclusion}

- The implementation of the educational program resulted in a significant improvement of nurses' performance pre and post hysterectomy surgery compared to pre educational program implementation.

- This proves that the present study is greatly important for nurses, patients and the overall nursing profession.

\section{Recommendations}

Based on the findings of the present study, the following recommendations are suggested:-

- Holding weekly meetings for nurses with their supervisors to exchange ideas and discuss the difficulties which 
face them in the management of the gynecological patients including hysterectomy women .

- Planning in-service training programs for all nurses regarding hysterectomy surgery must be conducted in order to improve, update and refresh their knowledge and qualify their practices dependent on recent evidence based practices in gynecological area.

- Written policies, protocol of care and guidelines should be developed for improving the quality of hysterectomy care.

- Facilities, equipment and supplies should be available to enable nursing staff to perform their role effectively.

- Studies on the effect of educational programs for nurses on postoperative outcome among women undergoing hysterectomy to improve the quality of care in the gynecological wards could be evaluated in another research.

- Reapplication of the study should be done under different circumstances including (large sampling, other settings, measurements and duration of management) in Egypt to ensure the generalization of the findings.

\section{References}

1. Ezzat L. An audit of hysterectomies at Aswan University Hospital in Upper
Egypt. The Egyptian Journal of Fertility of Sterility. 2019; 23 (1): 1-6.

\section{Alshawish E., Qadous Sh., Yamani}

A. Experience of Palestinian women after hysterectomy using a descriptive phenomenological study. The Open Nursing Journal. 2020; 14 (3): 74-9.

3. Chen B., Ren D., Li J., Li Ch. Comparison of vaginal and abdominal hysterectomy: a prospective nonrandomized trial. Pakistan Journal of Medical Sciences. 2014; 30 (4): 875-9.

\section{Fathy M., Al-Azony H., Hasanen E.,} Abd-Elhamid N. Total laparoscopic hysterectomy versus total abdominal hysterectomy in uterine tumors. The Egyptian Journal of Hospital Medicine. 2018; 72 (10): 5427-32.

5. Tonolini M. Multidetector CT of expected findings and complications after hysterectomy. Insights into Imaging.2018; 9 (3): 369-83.

\section{Michael D., Mremi A., Swai P.,} Shayo B., Mchom B. Gynecological hysterectomy in Northern Tanzania: A cross- sectional study on the outcomes and correlation between clinical and histological diagnoses. BMC Women's Health .2020; 10 (3):1 20-22.

7. Takai I., Yakasai I., Joy O., Ugwa E. An audit of gynaecological procedures 
performed at Aminu Kano teaching hospital, Kano. Journal of Basic and Clinical Reproductive Sciences. 2015; 4 (2): 64-69.

8. Ali H., Mohamed R., Riad R., Abd Elfadeel N. Effect of designed nursing care protocol on minimizing post hysterectomy complication at EL Manial university, Egypt. Egyptian Nursing Journal. 2018; 7 (3):49-53.

9. Adewale F. Hysterectomy; abdominal versus vaginal route: A comparative analysis of the indications and postoperative outcome, Nigeria. Pulsus J Surg Res. 2019; 3 (1):90-93.

10. Ali S., Farahat M., ElShafei M. Surgical approach to hysterectomy for benign gynecological diseases. The Egyptian Journal of Hospital Medicine. 2019; 77 (3): 5279-86.

\section{American College of Obstetricians} and Gynecologists. Choosing the route of hysterectomy for benign disease. Committee Opinion No. 701.Obstet Gynecol. (2017); 129 (6): 155-9.

12. Mettler L., Alkatout I. Laparoscopic subtotal hysterectomy: does it still have a stand?. International Journal of Gynecological Endoscopy. 2018; 2 (1):22- 8 .
13. Wilczyński M., Cieślak J., Malinowski A. Supracervical hysterectomy - the vaginal route. Videosurgery and Other Miniinvasive Techniques. 2014; 9 (2): 207-12.

14. Neis K., Zubke W., Fehr M., Römer Th., Tamussino K., Nothacker M. Hysterectomy for benign uterine disease. Deutsches Ärzteblatt International. 2016; 113(14): 242-49.

15. Neis K., Zubke W., Römer Th., Schwerdtfeger K., Schollmeyer T., Rimbach S., Holthaus B., Solomayer E., Bojahr B., Neis F., Reisenauer C., Gabriel B., Dieterich H., Runnenbaum I., Kleine W., Strauss A., Menton M., Mylonas I., David M., Horn L., Schmidt D., Teichmann A., Brandner P., Stummvoll W., Kuhn A., Müller M., Fehr M., Tamussino K. Indications and route of hysterectomy for benign diseases. Guideline of the DGGG, OEGGG and SGGG. 2016; 76 (4):350-64.

16. Nazik H. Laparoscopic approach to hysterectomy. Reviews in Health Care. 2013; 4 (2): 117-26.

17. Toppozada T., Elsayed S., Shehata G. Vaginal hysterectomy instead of abdominal hysterectomy in patients 
with previously scarred uterus. Austin Journal of Obstetrics and Gynecology. 2019; 6 (4): 1-6.

18. Clarke D., Geller E. Complications of hysterectomy. Obstetrics and Gynecology.2013; 121 (3):654-73.

19. Mehra A. Hysterectomy-"anger against the womb" a psychological perspective. Implications for Services., Gynecology and Obstetrics. 2014; 4 (12):1-3.

20. Shirinkam F., Alipoor Z., Chavari R., Ghaffari F. Sexuality after hysterectomy: a qualitative study on women's sexual experience after hysterectomy. International Journal of Women's Health and Reproduction Sciences. 2018; 6 (1): 27-35.

21. Selvanathan S., Acharya N., and Singhal S.Quality of life after hysterectomy and uterus-sparing hysteroscopic management of abnormal uterine bleeding or heavy menstrual bleeding. Journal of Midlife Health. 2019; 10 (2): 63-9.

22. Elsaied H., Nour Eldin S., Gad A., Mohamed H. Effect of uterine fibroid on women's health related quality of life and nursing management for patients undergoing hysterectomy. Assiut Scientific Nursing Journal. 2020; 8 (20): 12-27.
23. Malley A., Kenner C., Kim T., Blakeney B. The Role of the nurse and the preoperative assessment in patient transitions. AORN Journal. 2015; 102 (2): 181.

24. Taher S. The Impact of Preoperative Education on the Psychological and Physiological Aspects of Patients undergoing Abdominal Surgery. Published Master Thesis. An-Najah National University. Community Mental Health for Nurses, 2017.

25. Suresh Sh. Potter and Perry's Fundamentals of nursing. 2nd ed., India, Elsevier Health Sciences com., 2017; 500-5.

\section{Agency for Healthcare Research} and Quality. Ideal discharge planning, Available from https://www. ahrq.gov/sites/default/fileswysiwyg/pr ofessionals/systems/hospital/engagingf amilies/strategy4/Strat4_Implement_H andbook_508_v2.pdf Retrieved at 20-11-2020.

27. Adugbire B., Aziato L. Surgical patients' perspectives on nurses' education on post-operative care and follow up in Northern Ghana.BMC Nursing Journal. 2018; 29 (2): 17-29.

28. Glass Ch., Cash J. Family practice guidelines. 4th ed., New York, Springer Publishing com., 2017;11- 4. 
29. Sayin Y., Aksoy G. The Nurse's role in providing information to surgical patients and family members in Turkey: a descriptive study. ACORN Journal. 2012; 95(6):772-87.

30. Thilagavathi K., Rajeswari V. A pilot study to evaluate the effectiveness of preoperative teaching protocol on selected postoperative outcomes in terms of anxiety and depression status among women undergone hysterectomy. Asian Journal of Nursing Education and Research.2014; 4 (4):412-16.

31. Robert E. Reproductive, maternal, newborn, and child health disease control priorities. $3^{\text {rd }}$ ed., Washington, Black Ramanan Laxminarayan Marleen Temmerman Neff Walker com., 2016; 95.

32. Izetbegovic S., Alajbegovic J., Mutevelic A., Pasagic A., Masic I. Prevention of diseases in gynecology. International Journal of Preventive Medicine.2013; 4 (12): 1347-58.

33. Bielecka G., Mizgier M., Buks J., Krawczyk M., Wilczak M., Kędzia W. The Signs and symptoms of gynecological diseases. Polski Przegląd Nauk o Zdrowiu Journal. 2015; 4 (45): 297-300.

34. Bekar M., Guler H., Evcili F., Demirel G., Duran O. Determining the knowledge of women and their attitudes regarding gynecological cancer prevention. Asian Pacific Journal of Cancer Prevention. 2013; 14 (4): 55-59.

\section{Fram K., Saleh S.,Sumrein I.} Indications for a hysterectomy at Jordan University Hospital : A teaching hospital experience. Jordan Medical Journal. 2013; 47(3):201-9.

36. Turner L., Shepherd J., Wang L., Bunker C., Lowder J. Hysterectomy surgery trends: a more accurate depiction of the last decade?. Am Journal Obstet Gynecol. 2013; 208 (4): 277-81.

37. Farman A., Kousar R., Hussain M., Waqas A., Gillani S. Impact of job satisfaction on quality of care among nurses on the public hospital of Lahore. Saudi Journal of Medical and Pharmaceutical Sciences. 2017; 3(6):511-19.

38. Agu B. Patients and Nurses Attitudes to Hysterectomy and Postoperative Pain. Published Doctoral Thesis. Walden University. Philosophy Health care Administration, 2017.

\section{Belal Gh., Gaheen M., Mohamed F.}

The educational needs among obstetrical and gynecological nurses in El-Gharbia Governorate. Journal of 